\title{
ENSAIOS
}

\section{ASPECTOS JURÍDICOS DA PUBLICIDADE INFANTIL}

\section{RESUMO}

O Brasil não dispõe de um diploma legislativo específico sobre a publicidade infantil, o que gera uma série de repercussões negativas sobre o comportamento da criança e do adolescente, especialmente no que tange ao incremento da ânsia consumista desta parcela considerada hoje bastante considerável de consumidores. Os mecanismos utilizados por empresas de produtos ou serviços direcionados para este público específico, que estimulam e induzem o interesse na aquisição desses bens, deparam-se com um campo de ampla liberdade e imunidade quase que integral a limitações ou restrições, como consequência justamente da lacuna legislativa pertinente à matéria. Até existem instrumentos normativos que regem o assunto, a exemplo do Código de Defesa do Consumidor e do Estatuto da Criança e do Adolescente, porém tal regramento incide apenas indiretamente sobre a questão da publicidade infantil, cujo regramento limita-se àquele criado no âmbito da entidade privada de regulação da publicidade, o Conselho Nacional de Autorregulação Publicitária (CONAR) que, não obstante o esforço e a nobreza de suas intenções, não supre a contento a atividade regulatória e fiscalizadora da propaganda e da publicidade infantil. $\mathrm{O}$ presente ensaio, portanto, tem por objeto, justamente, as consequências jurídicas da inércia do legislador ordinário frente a assunto tão delicado e, ao mesmo tempo, de solução urgente.

Palavras-chave: Aspectos jurídicos. Publicidade infantil.

\section{INTRODUÇÃO}

Marcos José Nogueira de Souza Filho marcosjnsfilho@hotmail.com Mestre em Direito e Especialista em Direito Público. Professor de Instituições de Direito no Curso de Administração e de Direito Administrativo no Curso de Direito do Centro Universitário Christus - UNICHRISTUS.
A propaganda constitui elemento essencial no bom funcionamento da empresa. Afinal, é por meio dela que a marca e o produto são levados ao conhecimento do consumidor, estimulando-o à aquisição e alertando-o dos benefícios da compra do produto. Não obstante, em não raras oportunidades, a propaganda cumpre seu desiderato de forma abusiva, desvirtuada e inventiva, embutindo no pensamento do consumidor fisionomia que o produto, em verdade, não possui.

Tal cenário se evidencia de forma mais grave quando o público para quem a propaganda se dirigia é formado por crianças e 
adolescentes, que, a rigor, possui menor capacidade crítica e de racionalização das informações ali contidas, gerando um senso consumista de desejo pelo produto não baseado na necessidade, mas pelo mero imperativo de possuir.

Torna-se, assim, mas fácil atingir a ânsia de consumo do público infantil e juvenil, pois mais acessível à absorção das informações perpassadas na propaganda, induzindo-o à aquisição de um produto que, a priori, não lhe é indispensável. Propagandas de brinquedos, vestuário e alimentos são, muitas vezes, produzidas no intuito de atingir esta parcela do público, em razão justamente da acessibilidade.

O cenário se agrava em razão da inexistência de órgão ou entidade pública competente exclusivamente para lidar com a fiscalização e o controle da propaganda abusiva. E pior: o país não dispõe de instrumento legal que regulamente a matéria, restando promessas e projetos, mas nada inda efetivo e incisivo, o que permite a ampla liberdade no momento da divulgação de produtos pelas empresas.

Este ensaio se propõe, diante disto, a tratar de como a ciência jurídica pode contribuir para a solução do problema, restringindo a publicidade infantil e fazendo decrescer o sentimento consumista do jovem brasileiro, hoje em nível acima do tolerável e do admissível.

\section{FUNCCÕES DA PROPAGANDA E DA PUBLICIDADE E SUA IMPORTÂN- CIA PARA A ATIVIDADE EMPRE- SARIAL}

A empresa, visando ao incremento de suas atividades, corriqueiramente promove mecanismos de divulgação de sua marca e de seus produtos, alcançando, assim, o maior número possível de potenciais consumidores e adquirentes de seus produtos. Exemplo de tais meios são os comerciais televisivos, outdoors, rádio, links em sítios da internet, revistas e jornais, bem como material panfletário, entre outros menos convencionais.

Toda atividade humana, seja ela profissional ou não, deve ser cercada por parâmetros éticos que precisam estar presentes em qualquer conduta individual, promovendo a harmonia social e o bom convívio interno na comunidade. Quanto à atividade empresarial propriamente dita, a atuação da empresa deve permear pela lisura e pela lealdade para com seus clientes e concorrentes, evitando inserir-se sem situações antijurídicas passíveis de punição institucional. As informações publicadas de forma inverídica ou abusiva acabam por gerar descontentamento no próprio público para quem os serviços ou produtos da empresa são dirigidos.

Por essa razão, a boa publicidade, marcada por informações fidedignas e compatíveis com a realidade, não é só obrigação jurídica e moral da empresa, mas afeta positivamente sua imagem perante a própria clientela. Assim, tal publicidade fatalmente cumpre sua função social de forma plena, atingindo potenciais consumidores e imunizando a imagem da empresa.

No Brasil, é o que também impõe o Código de Defesa do Consumidor:

\begin{abstract}
Art. 31. A oferta e apresentação de produtos ou serviços devem assegurar informações corretas, claras, precisas, ostensivas e em língua portuguesa sobre suas características, qualidades, quantidade, composição, preço, garantia, prazos de validade e origem, entre outros dados, bem como sobre os riscos que apresentam à saúde e segurança dos consumidores (BRASIL, 1990a, online).
\end{abstract}

De qualquer forma, a publicidade deve ser entendida como o conjunto de mecanismos tendentes a estimular o consumidor à aquisição de um bem ou serviço. A publicidade, portanto, constrói e solidifica o elo entre a empresa - prestadora de serviços ou fornecedora de produtos - e seu cliente.

Segundo a doutrina, a principal finalidade da publicidade é a persuasão. Persuadir, para Robert Leduc, significa "obter do consumidor uma mudança de atitude propícia a criar nele comportamento que o predisponha à compra. [...]" Essas técnicas de persuasão, segundo o 
autor francês, agem "sobre a memória, criando uma espécie de reflexo mental próprio a provocar a compra." (LEDUC, 1977, p. 55-56).

O cenário explicita a real e efetiva finalidade da publicidade, que nada mais é do que o estímulo e a indução à aquisição de um produto ou serviço que leva o nome da empresa. Por mais discutível e polêmico que pareça ser esse fim, dado que é facilmente transponível a barreira ética que o permeia, a publicidade intrinsecamente se faz presente na atividade empresarial, que não pode abrir mão deste eficaz mecanismo de comunicação com seu potencial cliente.

Tanto que há permissivo legal da publicidade encontrado no Código de Defesa do Consumidor, cujo art. 36 prevê e autoriza a publicidade, mas impõe que sua veiculação seja fácil e verdadeiramente identificada como publicidade, e não como notícia ou aviso. Ou seja, a pessoa para quem a publicidade é dirigida deve reconhecer, de plano, tratar-se de publicidade e não de nenhuma outra forma de comunicação. Rege, nestes termos, o Código: "A publicidade deve ser veiculada de tal forma que o consumidor, fácil e imediatamente, a identifique como tal." (BRASIL, 1990a, online).

Dito isso, parece conveniente apresentar, neste momento, a diferença teórica entre a publicidade, que se está aqui a tratar, e a propaganda, que possui abrangência mais significativa e ultrapassa os possíveis clientes de uma empresa. Em verdade, enquanto a propaganda tem finalidade empresarial, divulgando o serviço ou o produto da empresa com intuito de venda, a publicidade possui natureza extra empresarial e se insere no âmbito político, econômico, social, ideológico ou partidário.

Também é o que ensina Guy Durandin, para quem:

A propaganda e a publicidade têm em princípio campos de aplicação diferentes: fala-se geralmente de publicidade quando se trata da área comercial, e propaganda quando de problemas de ordem política, ou de interesse geral. Mas ambas têm o mesmo objetivo genérico: modificar a conduta das pessoas (DURANDI, 1997, p. 14).

Suzana Maria Pimenta Catta Preta Federichi não apresenta entendimento diferente:

Vulgarmente tratadas como sinônimas, e embora servindo ao mesmo propósito de dar conhecimento público de algo, a doutrina difere a propaganda da publicidade, por divulgar e inserir produtos e serviços de mercado de consumo, ao contrário da primeira, que serve à divulgação de idéias, sejam elas políticas, filosóficas ou religiosas (FEDERICHI, 1999, p. 67).

Do exposto, mostra-se oportuno esclarecer que o propósito do presente artigo é analisar as consequências diretas da propaganda dirigida ao público infantil e sua repercussão no Direito, não se preocupando com a finalidade e a função da publicidade neste contexto, em que pese o termo "publicidade infantil" possuir maior atrativo didático. Eis o porquê da utilização desta última expressão no título deste breve ensaio.

Serão verificados, assim, os aspectos essencialmente jurídicos da propaganda infanto-juvenil e seus efeitos quase sempre maléficos sobre o público a quem se dirige.

\section{O PROBLEMA DA PUBLICIDADE E DA PROPAGANDA FALSA OU ABUSIVA}

Conforme noticiado há poucas linhas, a propaganda constitui mecanismo inerente à atividade empresarial de busca e coleta de pessoas passíveis de se transformarem em consumidores contumazes dos serviços e/ou dos produtos que a empresa disponibiliza no mercado. Ocorre que, em não raras vezes, no cumprimento de sua função, a propaganda finda por ultrapassar a tênue e quase invisível linha que divide a boa publicidade daquela de caráter duvidoso.

Mais comuns do que se imaginam são casos de iniciativas publicitárias que extrapolam 
limites convencionais do bom senso e da razão, aliciando de forma condenável o consumidor, especialmente aqueles de mais fácil convencimento e que formam o público infantil - o qual, aliás, constitui hoje parcela considerável de consumidores de certos produtos e serviços que lhes são inerentes.

Nesta conjuntura, dá-se razão ao delineamento do denominado princípio da veracidade, o qual deve permear a atividade propagandística comercial, revestindo de informações verdadeiras as mensagens publicitárias sobre certo serviço ou produto. Tal princípio ganha ainda mais relevo quanto tem por foco o público infanto-juvenil. Bruno Miragem, discorrendo sobre o assunto a atribuindo este cuidado ao Código de Defesa do Consumidor, assim se manifesta:

O CDC estabelece um dever de informar agravado com relação a certo público-consumidor, em vista da necessidade de se proteger determinados grupos de consumidores, como as crianças [...], a quem muitas vezes é endereçada publicidade com motivos fantasiosos ou irreais (personagens de desenho animado, pessoas que voam, dentre outros). Não se trata de coibir o recurso a técnicas normais de persuasão, ou mesmo que tornam a publicidade mais agradável. Apenas é vedada a utilização destas técnicas de modo a aproveitar-se da falta de discernimento das crianças, sob pena de esta publicidade ser considerada ilícita, porque abusiva (MIRAGEM, 2014, p. 257).

Não obstante a ausência de instrumento normativo regulatório específico sobre a publicidade e a propaganda, destacam-se no atual ordenamento jurídico pátrio os dispositivos legais pertinentes ao assunto e extraídos do Código de Defesa do Consumidor, que preveem a publicidade ilícita e a proíbe em suas modalidades enganosa e abusiva: "É proibida toda publicidade enganosa ou abusiva." (BRASIL, 1990a, online).
Seja em sua modalidade enganosa, seja na abusiva, a publicidade deve ser condenada por descumprir seu papel essencial de informação ao consumidor, pois tal informação fatalmente o induz a erro, prejudicando-o ao adquirir um serviço ou bem que, se real conhecedor de suas características, não os teria adquirido.

Suzana Maria Pimenta Catta Preta Federichi também alude sobre a dupla maneira pela qual se pode apresentar a publicidade irregular a partir do tratamento jurídico dado à matéria pelo Código de Defesa do Consumidor:
A Lei $\mathrm{n}^{\circ} 8.078 / 90$, inovadora no tra- tamento à publicidade, criou duas categorias de publicidade nociva, a enganosa e a abusiva. A publicida- de enganosa está diretamente ligada àquilo que pretende inserir no merca- do, ou seja, à natureza do serviço ou do produto. É a publicidade que induz ou simplesmente é capaz de induzir o consumidor a erro na eleição do pro- duto, e sua proscrição visa uma sani- dade na oferta. A publicidade abusiva, por sua vez, está relacionada à própria forma de abordagem do consumidor, não sendo obrigatório qualquer víncu- lo da nocividade da publicidade com a lisura do produto. $\mathrm{O}$ rol de condutas é enumerativo, sendo impossível ao legislador elencá-las exaustivamente (FEDERICHI, 1999, p. 69).

Por publicidade enganosa, entende-se a partir de seu conceito legal:

Qualquer modalidade de informação
ou comunicação de caráter publicitá-
rio, inteira ou parcialmente falsa, ou,
por qualquer outro modo, mesmo por
omissão, capaz de induzir a erro o con-
sumidor a respeito da natureza, carac-
terísticas, qualidade, quantidade, pro-
priedades, origem, preço e quaisquer
outros dados sobre produtos e serviços
(BRASIL, 1990a, online).

Portanto, desvirtuam-se as características do serviço ou do bem, omitindo informação 
essencial e existente ou apresentando, como real, característica inexistente. Também se revela mentirosa a publicidade que esconde perigos existentes, ofertando produto nocivo como se fosse imune a riscos.

O público infantil se coloca com frequência na condição de destinatário de mensagens publicitárias enganosas, comumente em relação a brinquedos. Aviões em miniatura que, no comercial, voam sozinhos, não o fazem na realidade, limitando-se a peça publicitária a informar que as imagens foram produzidas por computador, como se tal informação fosse compreensível pela criança.

Mais graves são os brinquedos que reproduzem ou são criados no formato de alimentos, muitos até com o odor que lhes é característico e embutido de forma artificial, sem que haja a informação do risco no filme publicitário. Isso também ocorre com brinquedos formados por peças minúsculas, facilmente ingeridas, quando a montagem da peça publicitária os mostra já prontos, escondendo (a) o risco do manuseio de peças pequenas por crianças e (b) a dificuldade na montagem do brinquedo, muitas vezes só possível com ajuda de adultos.

Enfim, na publicidade, mentira é tudo que "consiste em atribuir a um produto mais qualidades do que ele tem, e receber benefícios importantes em troca de um gasto relativamente pequeno" segundo o magistério de Durandin (1997, p. 29). tendida:

Já por publicidade abusiva, deve ser en-

A publicidade discriminatória de qualquer natureza, a que incite à violência, explore o medo ou a superstição, se aproveite da deficiência de julgamento e experiência da criança, desrespeita valores ambientais, ou que seja capaz de induzir o consumidor a se comportar de forma prejudicial ou perigosa à sua saúde ou segurança (BRASIL, 1990a, online).

A publicidade abusiva tem mais relação com a matéria apresentada neste trabalho aca- dêmico, pois - inclusive expressamente - aduz sobre a condição de vulnerabilidade da criança, que, a rigor, possui menor discernimento acerca da realidade das informações perpassadas pelo comercial televisivo ou por qualquer outro meio publicitário de divulgação de produtos infantis.

Nesta modalidade de publicidade, não há omissão de informações necessárias ou apresentação de caracteres irreais. Não há mentira, portanto, mas pode persistir a indução ao erro. Abusiva é a publicidade que se impõe ao consumidor de maneira contrária aos bons costumes, à ética, à moral, à segurança, à saúde, aos valores familiares e ao meio ambiente.

A oferta de determinado produto alimentício, especialmente aquele de preferência do público infantil, sem a informação de que seu consumo excessivo acarreta danos à saúde - ou o uso exagerado deste produto no filme publicitário, estimulando quem o assiste a proceder da mesma forma; a "adulterização" do comportamento infantil, por meio de imagens de crianças cumprindo funções tipicamente adultas, como o uso de sandálias de salto alto e maquiagens; o estímulo à violência, por meio de exposição de brincadeiras com brinquedos que reproduzem fielmente armas de fogo ou que se aparentam com armas, a exemplo das que espirram água; a erotização da brincadeira, como a disputa entre garotos pelo reconhecimento da mocinha e o uso de poucas roupas pelas crianças são exemplos de comerciais televisivos geridos de forma abusiva.

Neste diapasão, pode-se atribuir ao Código de Defesa do Consumidor a nobre responsabilidade de regular normativamente a publicidade de bens ou serviços que o mercado disponibiliza aos consumidores, protegendo-os contra as não raras inverdades e abusividades cometidas nas campanhas publicitárias modernas. Constitui, portanto, direito essencial do consumidor "a proteção contra a publicidade enganosa e abusiva, métodos comerciais coercitivos ou desleais", como, aliás, está descrito no art. $6^{\circ}$, inc. IV, do aludido Código (BRASIL, 1990a, online).

Não obstante, as regras ali contidas são demasiadamente genéricas e não atacam a fundo 
a questão específica da publicidade para crianças e adolescentes, que são aqueles mais propícios à absorção de informações inverídicas e abusivas veiculadas em comunicações publicitárias.

\section{A CRIANÇA E O ADOLESCENTE NA QUALIDADE DE CONSUMIDORES E A HIERARQUIA DE VALORES}

Historicamente, pode-se dizer que o surgimento e a consolidação da publicidade direcionada especificamente ao público infantil têm data relativamente recente, pois antes, as empresas não enxergavam na criança e no adolescente potenciais consumidores, restringindo suas atenções e iniciativas ao público adulto, equivocadamente entendido como o detentor exclusivo do poderio financeiro e da capacidade de consumo.

Somente na segunda metade do século passado, a publicidade descobriu esta parcela significativa de potenciais consumidores, ávidos não somente pelos produtos especificamente para eles fabricados (brinquedos, roupas, alimentos etc.), mas também para aqueles outros, de cunho adulto, da mesma forma passaram a ser desejados (filmes, maquiagem, joias e bijuterias, relógios etc.).

$\mathrm{O}$ incremento deste tipo de publicidade é apontado por Inês Silvia Vitorino Sampaio como característico dos meados da década de 80, quando se verifica:

A explosão dos programas infantis e o crescimento de sua importância na mídia. Nas publicações especializadas da área de propaganda e marketing, a "síndrome infantil" é identificada. A criança e o adolescente deixam de ser uma questão de interesse particular dos pais e educadores, tornando-se algo do interesse da propaganda, particularmente da publicidade e do marketing (SAMPAIO, 2000, p. 147).

O mercado hodierno reconhece nas figuras da criança e do adolescente potencial e fortíssimo segmento de consumidores e geradores de lucros, não mais somente em relação aos produtos e serviços essencialmente infanto-juvenis, mas também aqueles que, há pouco, eram usufruíveis apenas pela comunidade adulta.

Esta conjuntura também é visualizada por Inês Silvia Vitorino Sampaio, em cujo estudo se encontram os motivos por meio dos quais a criança ocupa hoje papel de destaque em termos de consumo:

O reconhecimento da participação destacada da criança no mercado de consumo brasileiro impulsiona a sua maior visibilidade na mídia. A criança é mais interpelada pela publicidade que reconhece: (1) a sua condição privilegiada de consumidor atual, com um poder razoável de decisão sobre as compras de artigos infantis; (2) de consumidor do futuro, a ser precocemente cortejado tendo em vista o processo de fidelização de marca; e (3) o seu poder de influência sobre itens de consumo da família (SAMPAIO, 2000, p. 152).

Tal cenário - relativo à situação da criança como efetiva consumidora em larga escala - seria isento de críticas se as empresas não lançassem mão de procedimentos espúrios com o fito de, ardilosamente, comercializar de forma excessiva, abusiva e, às vezes, mentirosa, atingindo a comunidade infantil em razão da acessibilidade e da ingenuidade que esta apresenta.

A publicidade destinada ao adulto tem configuração totalmente diferenciada daquela voltada para a criança, não somente em função do produto em si, mas também pela linguagem utilizada para passar a mensagem de persuasão à aquisição do que é ofertado pela empresa. Geralmente, o uso excessivo de cores e o entusiasmo exagerado do narrador são características peculiares à propaganda infantil, pois estimulam o senso consumista e a necessidade - no íntimo da criança, é necessidade mesmo - de obtenção do produto.

Os sentimentos de (a) inferioridade das crianças que têm o produto e (b) superioridade das que não têm são gerados propositadamente 
pelo conteúdo do filme publicitário, como se realmente houvesse a necessidade de aquisição como requisito para o alcance da felicidade e da saciedade. Ocorre que, em não raras vezes, os produtos infantis se revestem da condição de bens supérfluos e dispensáveis que, se não unilateralmente impostos ao desejo infantil, não fariam qualquer falta.

A ânsia da criançada por produtos especificamente para ela fabricados tem repercutido negativamente no próprio orçamento da família brasileira que, inerte, se vê a mercê dos abusos cometidos pelas indústrias de produtos infantis e por seus respectivos projetos de marketing. Estes, de resto, cumprem efetivamente o papel em função do qual devem sua existência: de induzir, estimular e fazer crescer o consumo infantil.

A conjuntura implica a capacidade da criança de induzir as opções dos pais por ocasião da visita ao supermercado. "Crianças influenciam os pais nas compras", assevera Tânia da Silva Pereira, que arremata:

Os alimentos comprados em muitas casas são, em parte ditados (ou sugeridos) pelas crianças. Mas nem só aos alimentos se restringe essa influência; sugestões para produtos de limpeza e higiene pessoal também são feitas. Os conhecimentos em nutrição, preferências ou tentativas de compra são influenciados pelos comerciais PEREIRA, 1996, p. 464).

O desequilíbrio nas contas da família brasileira se dá, em não raras vezes, em razão do que a doutrina chama de "alteração da hierarquia de valores", segunda a qual o consumidor dá preferência ao supérfluo em detrimento do necessário. E a propaganda, especialmente a infantil, tem sua parcela de responsabilidade neste cenário adverso: A propaganda, diz Robert Leduc,

altera certa hierarquia dos valores, fazendo com que se comprasse o acessório antes do essencial. Na realidade, a hierarquia dos valores depende muito mais do que se convencionou chamar "normas sociais de consumo", que traduzem o comportamento da coletividade e que são formadas pelo hábito, as crenças, os costumes, a família, o meio e as leis (LEDUC, 1977, p. 387-388).

A criança e o adolescente, por se constituírem como meros dependentes econômicos, e não os efetivos provedores do sustento familiar, são mais acessíveis ao impulso consumista, o que, se não afeta direta e negativamente as contas da família, causa transtorno ao ambiente familiar quando vêm sua ânsia por bens ou serviços constrangida.

A doutrina publicitária defende sua função e seu papel na economia de mercado alegando que o próprio consumidor possui capacidade de distinguir o que deve e o que não deve ser comprado. Assim, a aquisição equivocada de um produto ou serviço não deve ser responsabilidade de quem vende ou de quem anuncia o bem, mas somente daquele que efetua a compra. Tal doutrina, à primeira vista, parece convenientemente supervalorizar a capacidade do consumidor.

Para Robert Leduc, entusiasta da publicidade e da propaganda, o cliente sabe até onde alcança sua capacidade de consumo:

Há diversos meios de se proteger o consumidor, sendo que o primeiro entre eles talvez seja a autoproteção, a proteção do consumidor exercida por ele mesmo. Nada poderá substituir a necessidade do consumidor de se conduzir de modo razoável, exercendo seu espírito crítico, suas faculdades de observação e de julgamento, quando compra um produto (LEDUC, 1977, p. 403).

Reconhece-se que há certa razão nas palavras transcritas. Inobstante, não parece que tal posicionamento se enquadre na situação da criança e do adolescente, pois estes, em razão do senso e do discernimento reduzido em relação a assuntos financeiros, não conseguem a contento distinguir o necessário do supérfluo. 
Ademais, há incontestável excesso de publicidade nos meios de comunicação destinados ao público infantil. Se, para o adulto há o cinema, a revista, o jornal, o rádio etc., para a criança a comunicação quase que se resume à televisão. E é aqui que reside a gravidade da questão: é na TV que se multiplicam os anúncios de brinquedos e demais produtos infantis, especialmente nos horários típicos em que a criança está à frente do aparelho de televisão ou nos canais específicos para o público infanto-juvenil que a TV a cabo e/ou por assinatura disponibilizam.

Assim, o acesso da publicidade à criança é imediato, mesmo quando se trata de resenhas propagandísticas abusivas ou mentirosas. No íntimo, o adolescente e, principalmente, a criança costumam acreditar integralmente em todas as informações que lhe são perpassadas, do que se aproveitam as campanhas publicitárias. As crianças não têm o discernimento crítico para a distinção entre o certo e o errado, entre o justo e o injusto, entre o necessário e o dispensável.

Guy Durandin apresenta dados que apontam a gravidade das consequências da publicidade infantil enganosa e/ou abusiva devido ao absoluto desconhecimento do funcionamento das campanhas publicitárias pelas crianças, o que torna o impulso consumista mais fácil de ser atingido:

As crianças, até a idade de dez anos, e até mais, não sabem nada da organização da publicidade e da profissão publicitária. Ignoram a existência das agências de publicidade e, quando interrogadas sobre a origem dos comerciais na televisão, atribuem-na aos próprios fabricantes dos produtos, ou então ao "diretor" da televisão. Ignoram assim a natureza e a multiplicidade dos processos realizados para seduzi-las (DURANDIN, 1997, p. 38).

A condição de vulnerabilidade da criança e do adolescente sobre o tema, inobstante a falta de tratamento legislativo específico, é reconhecida pelo Estatuto da Criança e do Adolescente (Lei $n^{\circ} 8.069$, de 13 de Julho de 1990), o qual lhes garante o "direito a informação, cultura, lazer, esportes, diversões, espetáculos e produtos e serviços que respeitem sua condição peculiar de pessoa em desenvolvimento", nos exatos termos do art. 71 (BRASIL, 1990b, online).

Apesar disso, não há, no Estatuto ou sequer em leis esparsas, qualquer normatização específica sobre a questão da propaganda ou da publicidade infantil. Tal lacuna legislativa permite, portanto, a ocorrência das mais diversas situações, a maioria delas de qualidade discutível e, portanto, passível de críticas por aqueles que nada mais pretendem do que proteger o público infantil do estímulo dado pelas campanhas publicitárias ao sentimento consumista.

\section{A LACUNA LEGISLATIVA ESPE- CÍFIC A SOBRE PUBLICIDADE INFANTIL}

O tratamento da matéria pelo ordenamento jurídico existente se dá em sua forma tácita, aplicando-se à problemática da publicidade infantil dispositivos apenas indiretamente pertinentes do Código de Defesa do Consumidor e do Estatuto da Criança e do Adolescente. Em função do tratamento meramente indireto, a questão da publicidade infantil abusiva e/ou enganosa não está resolvida sob o ponto de vista jurídico.

Ora, se ao particular é juridicamente possível fazer tudo o que a lei expressamente não proíbe, ou seja, "ninguém será obrigado a fazer ou deixar de fazer alguma coisa senão em virtude de lei” (BRASIL, 1988, online), em atenção ao princípio constitucional da legalidade (art. $5^{\circ}$, inc. II), as empresas e as firmas de publicidade, a rigor, não se depararam com limitações jurídicas específicas e veem, por isso mesmo, ampliada demasiadamente sua liberdade de expor seus serviços e produtos das mais variadas formas possíveis, o que, em não raras vezes, debanda para a publicidade abusiva e/ou enganosa.

$\mathrm{O}$ que se vê, quando se depara atentamente com a publicidade infantil, é que esta se manifesta basicamente por duas formas específicas: (a) por meio de comerciais e campanhas publicitárias diretas, que apresentam filmes re- 
alizados por firmas de publicidade para empresas que disponibilizam bens ou serviços infantis, e geralmente aproveitam os intervalos dos programas infantis para divulgarem suas marcas; e (b) por meio indireto, por meio desses próprios programas infantis que, por sua vez, também cumprem parcela de responsabilidade no incremento do consumismo entre os menores, ao vincular marcas de produtos à imagem do(a) apresentador(a).

Acerca deste último segmento, leciona Inês Silvia Vitorino Sampaio:

A atratividade dos programas se fundamenta no carisma de seus apresentadores e nos desenhos animados, que respondem por parcela expressiva da programação. As emissoras investem na imagem de seus apresentadores que, por sua vez, emprestam sua imagem de estrelas a produtos e marcas. O sucesso de vendas implica novas verbas para o financiamento desses mesmos programas e a valorização dos mesmos apresentadores. Num processo similar, as emissoras lançam, também, séries cujos personagens, através de licenciamentos, são associados a um conjunto de produtos anunciados nos intervalos da programação - caso dos comerciais - ou no interior da mesma - caso do merchandising (SAMPAIO, 2000, p. 149).

Assim, é possível deduzir que, desde o surgimento deste tipo de marketing, já deveria ter sido criado um instrumento normativo para disciplinar especificamente a publicidade infantil, no que tange à questão conceitual, às limitações e restrições, às liberdades, aos impedimentos e às punições. Decerto, uma legislação sobre a matéria afrontaria uma série de direitos econômicos de fábricas e indústrias, e bem assim das firmas publicitárias, que restariam restringidas em sua atuação no mercado.

Alegariam, com certeza, cerceamento à liberdade constitucional de expressão e a vedação à censura, conforme previsão constitucional no art. $5^{\circ}$ : "é livre a manifestação do pen- samento, sendo vedado o anonimato" (inc. IV) e "é livre a expressão da atividade intelectual, artística, científica e de comunicação, independentemente de censura ou licença" (inc. IX) (BRASIL, 1988, online).

Tais prerrogativas, inseridas na lista de direitos fundamentais de $1^{\mathrm{a}}$ geração constante do art. $5^{\circ}$ da Constituição Federal, se aliam a outras proteções relativas à comunicação social, a saber: "Art. 220. A manifestação do pensamento, a criação, a expressão e a informação, sob qualquer forma, processo ou veículo não sofrerão qualquer restrição, observado o disposto nesta Constituição. [...] $\S 2^{\circ}$ - É vedada toda e qualquer censura de natureza política, ideológica e artística." (BRASIL, 1988, online).

Ocorre que, em nível constitucional, não se devem interpretar dispositivos constitucionais de forma isolada, senão através de estudo sistêmico. O princípio da unidade da Constituição (das Prinzip der Einheit der Verfassung), que encontra em Hesse (1991) seu expoente maior, aduz à necessidade de sistematização das normas com conteúdos próximos ou relacionados, evitando a consideração isolada da norma constitucional, que faz parte de um complexo formado a partir da inter-relação entre as normas constitucionais materialmente vinculadas entre si.

Nesses termos, se realmente está garantida a liberdade de manifestação do pensamento e vedada a censura, por outro lado há outros bens jurídicos tutelados constitucionalmente que, em conflito com os primeiros, podem e devem se sobressair. Está-se a tratar da proteção à família e, especialmente, à criança e ao adolescente; afinal tais elementos também fizeram por merecer proteção constitucional:
Art. 220. [...]
[...]
$\S 3^{\circ}$ - Compete à lei federal:
[...]
II - estabelecer os meios legais que garantam à pessoa e à família a pos- sibilidade de se defenderem de pro- gramas ou programações de rádio e televisão que contrariem o disposto no art. 221, bem como da propaganda 
de produtos, práticas e serviços que possam ser nocivos à saúde e ao meio ambiente.

[...]

Art. 227. É dever da família, da sociedade e do Estado assegurar à criança, ao adolescente e ao jovem, com absoluta prioridade, o direito à vida, à saúde, à alimentação, à educação, ao lazer, à profissionalização, à cultura, à dignidade, ao respeito, à liberdade e à convivência familiar e comunitária, além de colocá-los a salvo de toda forma de negligência, discriminação, exploração, violência, crueldade e opressão (BRASIL, 1988, online).

Especificamente sobre o conteúdo do $\S 3^{\circ}$ do art. 220 da Constituição, que atribui à lei federal - ainda não editada - a criação de meios legais que garantam à pessoa e à família a possibilidade de se defenderem da propaganda de produtos, práticas e serviços nocivos, escreve Suzana Maria Pimenta Catta Preta Federichi que "o próprio constituinte previu situações em que a publicidade pose ser represada em função de outros bens jurídicos mais relevantes." (FEDERICHI, 1999, p. 81).

Entretanto, mesmo com o tratamento normativo indireto pelo Código de Defesa do Consumidor, que se limita a disciplinar a publicidade impedindo-a nas modalidades abusiva e/ou enganosa, e pelo Estatuto da Criança e do Adolescente, que resguarda os interesses infanto-juvenis sem especificar a questão publicitária, e bem assim o disciplinamento constitucional da comunicação social, que protege a família e o menor contra a propaganda de produtos nocivos, o certo é que a falta de legislação própria dificulta sobremaneira o controle e a fiscalização das entidades publicitárias e do que fazem para atrair o público e incentivá-lo ao consumo.

Destaca-se que a inércia não é do Estado ou do Município, mas da União Federal, especificamente do Congresso Nacional, a quem a Constituição Federal atribuiu a competência privativa para legislar sobre propaganda, ex vi o disposto no art. 22: "Compete privativamente à União legislar sobre: [...] XXIX - propaganda comercial." (BRASIL, 1988, online).

O que existe em termos efetivos é a tramitação de um Projeto de Lei (no 5.608/2013), de iniciativa do Deputado Federal Rogério Carvalho (PT/SE), que regulamenta a publicidade infantil de alimentos (BRASIL, 2013). Atente-se para o teor daquilo que poderá vir a se tornar lei e, portanto, imperativa e obrigatória:

Art. $1^{\circ}$ Fica proibida a publicidade, dirigida a crianças, de alimentos e bebidas pobres em nutrientes e com alto teor de açúcar, gorduras saturadas ou sódio.

$\S 1^{\circ}$ A vedação se estenderá no período compreendido entre 6 horas e 21 horas, no rádio e televisão, e em qualquer horário nas escolas públicas e privadas.

$\S 2^{\circ}$ Fica impedida a utilização de celebridades ou personagens infantis na comercialização, bem como a inclusão de brindes promocionais, brinquedos ou itens colecionáveis associados à compra do produto.

Art. $2^{\circ}$ A publicidade durante o horário permitido deverá vir seguida de advertência pública sobre os males causados pela obesidade (BRASIL, 2013, online).

Inobstante o projeto de lei limitar-se à publicidade infantil de alimentos, e não de qualquer produto ou serviço, já se vislumbra a iniciativa como um avanço legislativo em uma área quase que absolutamente desregrada.

Em âmbito genérico, envolvendo qualquer produto ou serviço destinado aos infantes, destaca-se o anterior Projeto de Lei $n^{\circ}$ 5921/2001, sob a autoria do Deputado Luiz Carlos Hauly (PSDB/PR), visando à proibição definitiva de tal modalidade propagandística, ao pretender inserir no Código de Defesa do Consumidor dispositivo cujo teor seria "É também proibida a publicidade destinada a promover a venda de produtos infantis, assim considerados aqueles destinados apenas à criança." (BRASIL, 2001, online).

Decerto que os instrumentos normati- 
vos acima referidos encontram-se ainda em sua fase embrionária, pendentes de conclusão procedimental. E a gravidade da questão não se reduz à lacuna legislativa sobre publicidade infantil, mas se deve também à ausência de órgão ou entidade administrativa cuja área de atuação seja o controle da publicidade e da propaganda.

\section{A NATUREZA JURÍDICA DO CO- NAR E SUA CAPACIDADE NOR- MATIVA}

A questão da publicidade infantil imune à restrição pela ausência de regulamentação, somada à inexistência de estrutura administrativa regulatória e fiscalizadora, tem sua gravidade diminuída pela existência de uma entidade privada cujas funções específicas são zelar pela comunicação comercial e atuar como "órgão judicante nos litígios éticos que tenham por objeto a indústria da propaganda ou as questões a ela relativas." (CONSELHO NACIONAL DE AUTORREGULAMENTAÇÃO PUBLICITÁRIA, 2014a, online).

Destarte, existe um instrumento normativo a regulamentar a publicidade e a propaganda, criada no âmbito do próprio CONAR: o Código Brasileiro de Autorregulamentação Publicitária. Neste, há a previsão do impedimento às publicidades enganosas e/ou abusivas de que também tratou o Código de Defesa do Consumidor: "Os anúncios devem ser realizados de forma a não abusar da confiança do consumidor, não explorar sua falta de experiência ou de conhecimento e não se beneficiar de sua credulidade." (art. 23). (CONSELHO NACIONAL DE AUTORREGULAMENTAÇÃO PUBLICITÁRIA, 2014b, online).

Especificamente sobre a publicidade infantil, também se verifica no Código Brasileiro de Autorregulamentação Publicitária um regramento imperativo de como devem se comportar os publicitários neste campo:

Artigo 37 - Os esforços de pais, educadores, autoridades e da comunidade devem encontrar na publicidade fator coadjuvante na formação de cidadãos responsáveis e consumidores conscientes. Diante de tal perspectiva, nenhum anúncio dirigirá apelo imperativo de consumo diretamente à criança (CONSELHO NACIONAL DE AUTORREGULAMENTAÇÃO PUBLICITÁRIA, 2014b, online).

Não obstante a nobreza e a boa vontade da instituição referida, bem como a qualidade técnica da regulamentação por ela editada, estas não suprem a falta de um tratamento legislativo público e imparcial. Ora, o CONAR é pessoa jurídica de direito privado não integrante da Administração Pública, criado na forma de associação privada sem fins lucrativos, sendo seu corpo diretivo formado predominantemente por profissionais da área da propaganda, do marketing e da publicidade.

Desconhece-se qualquer caso de conduta recriminável por parte do CONAR que, ao que parece, é merecedor de elogios em sua árdua tarefa regulatória e fiscalizadora dos anúncios publicitários. Mas sempre age com um quê de parcialidade que, se não aparente, é presumível. E mais: é, ele próprio, entusiasta da liberdade de expressão comercial e da vedação à censura ou qualquer outra forma de limitação de tal liberdade, tanto que sua missão é "promover a liberdade de expressão publicitária e defender as prerrogativas constitucionais da propaganda comercial." (CONSELHO NACIONAL DE AUTORREGULAMENTAÇÃO PUBLICITÁRIA, 2014c, online).

No âmbito de seus procedimentos internos, há garantia plena do devido processo legal, do contraditório e da ampla defesa. E a atuação se dá sempre a posteriori, ou seja, o CONAR "não exerce censura prévia sobre peças publicitárias, já que se ocupa somente do que está sendo ou foi veiculado." (CONSELHO NACIONAL DE AUTORREGULAMENTAÇÃO PUBLICITÁRIA, 2014c, online).

O cenário também é retratado na doutrina de Rosane Leal da Silva:

Em algumas situações, o CONAR con- 
segue atuar e retirar dos meios de comunicação a publicidade que desrespeita ou explora a falta de julgamento do público infanto-juvenil. Porém, quando isso acontece, a publicidade já atingiu o seu objetivo, pois bastam alguns segundos de veiculação para uma anúncio publicitário influenciar uma criança (SILVA, 2011, p. 323).

De todo o exposto, a questão da ausência de regulamentação da publicidade infantil é apenas mitigada - mas não definitivamente resolvida - pelo esforço do CONAR e por sua atuação no controle da atividade publicitária. Mas, ao que parece, o que pais e educadores exigem, em verdade, é o cumprimento da função constitucional do Congresso Nacional em regular e restringir a propaganda comercial e a publicidade, especialmente aquela que mais arduamente vem sendo contestada por segmentos organizados da sociedade: a publicidade infantil.

\section{CONCLUSÃO}

A elaboração do artigo que agora se finda propiciou a pesquisa e o estudo sobre este assunto que é pouco abordado no campo jurídico, mas de importância prática indiscutível no âmbito da Administração e do Marketing; a questão da publicidade infantil e as consequências negativas da falta de sua regulamentação específica.

Compreendeu-se que não se está a tratar propriamente de publicidade, mas de propaganda: enquanto a primeira tem natureza geral e diversificada, abrangendo o campo da política, da ideologia, da religião, etc., esta assume um viés eminentemente comercial, intimamente ligado que está à atuação empresarial, especialmente em relação a empresas que sentem a necessidade de divulgar sua marca, seus bens e serviços, estimulando sua clientela à aquisição de seus produtos. Trata-se, portanto, de um conjunto de medidas essenciais ao bom funcionamento da atividade empresarial.

Ocorre que, em não raras vezes, a veiculação da marca, dos bens ou serviços da empresa se faz por meio de anúncios comerciais de parâmetros éticos duvidosos, através da chamada propaganda enganosa ou abusiva, conforme conceituação e tutela dada pelo Código de Defesa do Consumidor. Entretanto, o referido Código não teve o condão de regular especificamente a publicidade infantil, deixando, portanto, esta lacuna legislativa.

Também o Estatuto da Criança e do Adolescente perde a oportunidade de fazer o disciplinamento da matéria. Claro que há regras protetivas do infante no Estatuto, especialmente no que tange aos direitos à informação, à cultura, ao lazer etc., desde "que respeitem sua condição peculiar de pessoa em desenvolvimento" (art. 71) (BRASIL, 1990b, online). Mas tais regras se aplicam apenas indiretamente à celeuma publicitária, nada constando no Estatuto especificamente sobre anúncios, televisivos ou não, de estímulo ao consumismo dirigido a esta parcela de consumidores.

A Constituição Federal e seu extenso número de dispositivos também se olvidaram do disciplinamento do assunto. As regras genéricas de proteção à liberdade de expressão do pensamento e da vedação à censura, as quais, a rigor, garantiriam a ampla e irrestrita publicidade comercial, entram em conflito com as normas constitucionais de proteção à família e a seus valores, bem como à infância e à juventude.

O quadro não se mostra ainda mais desalentador graças a uma entidade privada de controle interno da atividade publicitária: o CONAR, que conta com instrumentos normativos que, de certa maneira, atenuam os efeitos causados pela inércia do legislador ordinário brasileiro e criam restrições e limitações à propaganda comercial.

Entretanto, aos olhos dos principais interessados na regulação da publicidade infantil, a exemplo de pais e educadores, a atuação do CONAR e a edição de regras pela associação não suprem a falta de normatização pública sobre o assunto, dada a justificada presunção de parcialidade que paira sobre aquela entidade privada. Misteres, portanto, a urgente edição de normas regulatórias públicas e a necessária criação de órgão administrativo com atribuição 
específica de fiscalizar e controlar a atuação das firmas publicitárias criadoras de anúncios que estimulem e agucem os anseios consumistas do público infantil.

Não se está, neste azo, a defender uma vedação absoluta à atividade propagandista empresarial destinada à clientela infanto-juvenil. Longe disso. Inobstante, o vácuo normativo estatal sobre o assunto, decerto, enseja o surgimento de iniciativas oportunísticas capazes de afetar negativamente o discernimento da criança, estimulando-a a um sentimento consumista cuja aquisição não é prudente sob o ponto de vista educacional. Daí o porquê do urgir da premente regulamentação específica a disciplinar esta seara publicitária.

\section{LEGAL ASPECTS OF ADVERTISING TO CHILDREN}

\section{ABSTRACT}

Brazil does not have a specific piece of legislation on advertising to children, which generates a number of negative effects on the behavior of children and adolescents, especially with respect to increased consumer craving in what is today a large group of people. The mechanisms used by product or service companies targeting specifically this audience, stimulating and inducing interest in acquiring said goods, are faced with larger freedom and are almost entirely immune to limitations or restrictions, precisely because of the legislative gap concerning this matter. Although certain legal instruments governing the subject, such as the Consumer Protection Code and the Statute of the Child and Adolescent, do exist, such norms focus only indirectly on the issue of advertising to children; the subject is only directly targeted by norms set up under by the private entity that regulates advertising, the National Council of Self-Regulation in Advertisement (CONAR), which, deploying its best efforts and the noblest of intentions, does not meet the requirements of satisfactorily regulating and supervising advertisement to children. This essay engaged preci- sely the legal consequences of the inaction of the legislator before such delicate and, at the same time, urgent matter.

Keywords: Aspects legal. Advertising children.

\section{ASPECTOS JURÍDICOS DE LA PUBLICIDAD INFANTIL}

\section{RESUMEN}

Brasil no dispone de un diploma legislativo específico sobre la publicidad infantil, lo que genera una serie de repercusiones negativas sobre el comportamiento de los niños y de los adolescentes, especialmente en lo que concierne el incremento de la ansia consumista de esta parcela actualmente bastante considerable de consumidores. Los mecanismos utilizados por empresas de productos o servicios direccionados a este público específico, estimulando e induciendo el interés en la adquisición de eses bienes, se deparan con un campo de amplia libertad y casi total inmunidad a limitaciones o restricciones, en función justamente de la laguna legislativa pertinente a la materia. Aunque existan instrumentos legales que disponen sobre el asunto, como el Código de Defensa del Consumidor y del Estatuto del Niño y Adolescente, dichas normas inciden apenas indirectamente sobre la cuestión de la publicidad infantil; la reglamentación de esta materia se queda limitada al ámbito de la entidad privada de regulación de publicidad, el Consejo Nacional de Autorregulación Publicitaria (CONAR), que, no obstante el esfuerzo y la nobleza de sus intenciones, no suple a contento la actividad regulatoria y fiscalizadora de la publicidad infantil. El presente ensayo, por tanto, tiene por objeto justamente las consecuencias jurídicas de la inercia del legislador ordinario frente a asunto tan delicado $\mathrm{y}$, al mismo tiempo, que exige solución urgente.

Palabras-clave: Aspectos jurídicos. Publicidad infantil. 


\section{LES ASPECTS JURIDIQUES DE LA PUBLICITE INFANTILE}

\section{RESUME}

Le Brésil ne dispose pas d'un diplôme législatif sur la publicité infantile, ce qui génère une série de répercussions négatives sur le comportement de l'enfant et de l'adolescent, spécialement en ce qui concern l'incrément de l'avidité consumériste de cette parcelle aujourd'hui considérable de consommateurs. Les mécanismes utilisés par les entreprises de produits ou de services dirigés à ce public spécifique, stimulant et induisant l'intérêt en acquérir ces biens, se retrouvent face à un champ d'ample liberté et d'immunité quasi intégrale à des limitations ou restrictions, en fonction justemente de cette lacune législative pertinent à la matière. Malgré le fait que certains instruments normatifs disposent sur la matière, comme le Code de défense du consommateur et le Statut de l'enfant et de l'adolescent, ces règlements n'incident que de manière indirecte sur la question de la publicité infantile; le règlement direct de la matière est limité à celui établis par l'entité privée de regulation de la publicité, le Conseil national d'autorégulation publicitaire (CONAR), qui, malgré tous ses efforts et la noblesse de ses intentions, n'arrive pas à réaliser l'activité de régulation et de fiscalisation de la publicité infantile. Le présent essai a, donc, pour objet les conséquences juridique de l'inertie du législateur ordinaire face à ce problème si délicat et, en même temps, demandant une solution urgente.

Mots-clés: Aspects juridiques. Publicité infantile.

\section{REFERÊNCIAS}

BRASIL. Constituição Federal de 1988. Promulgada em 5 de Outubro de 1988. Presidência da República, Brasília, DF, 1988. Disponível em: <http://www.planalto.gov.br/ccivil_03/ constituicao/constituição.htm>. Acesso em: 2 dez. 2017.
. Estatuto da Criança e do Adolescente. Lei ${ }^{0}$ 8.069, de 13 de Julho de 1990. Dispõe sobre o Estatuto da Criança e do Adolescente e dá outras providências. Presidência da República, Brasília, DF, 1990b. Disponível em: $<$ http://www.planalto.gov.br/ccivil_03/leis/ L8069.htm>. Acesso em: 2 dez. 2017.

Lei $n^{\circ} 8.078$, de 11 de Setembro de 1990. Dispõe sobre a proteção do consumidor e dá outras providências. Presidência da República, Brasília, DF, 1990a. Disponível em: $<$ http://www.planalto.gov.br/ccivil_03/leis/ L8078.htm>. Acesso em: 2 dez. 2017.

- Câmara dos Deputados. Projeto de Lei no 5.921, de 2001. Disponível em: $<$ http:// www.camara.gov.br/proposicoesWeb/fichadetramitacao?idProposicao $=43201>$. Acesso em: 2 dez. 2017.

Câmara dos Deputados. Projeto de Lei no 5.608, de 2013. Disponível em: <http:// www.camara.gov.br/proposicoesWeb/fichadetramitacao?idProposicao $=577703>$. Acesso em: 4 maio 2014.

CONSELHO NACIONAL DE AUTORREGULAMENTAÇÃO PUBLICITÁRIA. Estatuto Social do CONAR. Disponível em: <www.conar.org.br>. Acesso em: 4 maio 2014a.

Código Brasileiro de Autorregulamentação Publicitária Código e Anexos CONAR. Disponível em: $<$ http://www.conar. org.br/codigo/codigo.php>. Acesso em: 4 maio 2014b.

Missão. Disponível em: $<\mathrm{http}: / / \mathrm{www}$. conar.org.br/>. Acesso em: 4 maio 2014c.

DURANDIN, Guy. As mentiras na propaganda e na publicidade. Tradução de Antônio Carlos Bastos de Mattos. São Paulo: JSN Editora, 1997.

FEDERICHI, Suzana Maria Pimenta Catta Pre- 
ta. Publicidade abusiva: incitação à violência. São Paulo: Editora Juarez de Oliveira, 1999.

HESSE, Konrad. A força normativa da constituição. Porto Alegre: Fabris, 1991.

LEDUC, Robert. Propaganda: uma força a serviço da empresa. Tradução de Sílvia de Lima Bezera Câmara. São Paulo: Atlas, 1977.

MIRAGEM, Bruno. Curso de direito do consumidor. 5. ed. São Paulo: Revista dos Tribunais, 2014.

PEREIRA, Tânia da Silva. Direito da criança e do adolescente: uma proposta interdisciplinar. Rio de Janeiro: Renovar, 1996.

SAMPAIO, Inês Silvia Vitorino. Televisão, publicidade e infância. São Paulo: Annablume; Fortaleza: Secretaria de Cultura e Desporto do Estado do Ceará, 2000.

SILVA, Rosane Leal da. A exposição do público infanto-juvenil á publicidade subliminar on line: o caso do jogo Miss Bimbo. Pensar: revista de ciências jurídicas, Fortaleza, v. 16, n. 1, p. 311-331, 2011. 